Compêndio Gil Vicente. (coord.) José Augusto Cardoso Bernardes e José Camões. Edição conjunta da Imprensa da Universidade de Coimbra, Centro de Estudos de Teatro e Centro de Literatura Portuguesa

Christine Zurbach (CHAIA/Univ. Évora)

\title{
Gil Vicente em língua francesa
}

Não é objectivo deste breve estudo oferecer ao leitor uma reflexão aprofundada sobre a problemática da tradução em geral, mas apenas apresentar os resultados da pesquisa bibliográfica realizada em torno da recepção da obra de Gil Vicente em língua francesa, acompanhados por alguns comentários. No entanto, tendo em conta o reconhecimento hoje indiscutível da tradução enquanto objecto de estudo (Delabastita 2006), considero indispensável iniciar este contributo sobre a(s) tradução(ões) da obra do dramaturgo com algumas notas de carácter metodológico. Serão seguidas da lista dos resultados recolhidos, completada com apontamentos finais.

A tradução para a língua francesa de Gil Vicente representa um estudo de caso exemplar, no qual o investigador encontrará matéria para equacionar questões centrais nos estudos tradutológicos contemporâneos, tais como: a função intercultural da tradução, enquanto lugar revelador das relações de poder entre as literaturas e as culturas (Casanova 1999), sendo que, nesse campo, a literatura portuguesa se tem mantido numa posição geralmente periférica; a eventual especificidade genológica e técnica da tradução de/para o teatro (Bassnett 2003), sendo notória também a escassez do repertório do teatro de língua portuguesa traduzido para a língua francesa até finais do séc. XX; a definição sociocultural de um perfil do tradutor de Gil Vicente, e também do público destinatário deste tipo de repertório: quem traduz e para quem?

Sem pretensão à exaustividade, os dados apresentados que compõem o "dossiê Gil Vicente em língua francesa" resultam do levantamento realizado em bases de dados acessíveis em bibliotecas ou disponibilizados em websites de editoras. A lista obtida, que é apresentada a seguir numa sequência cronológica, contém um total de doze itens identificados como: a) dez publicações comerciais em livros, devidamente integradas na 
programação de cinco editoras, das quais duas francesas (Éditions Gallimard e Éditions Chandeigne) e as restantes portuguesas (Imprensa Portugal-Brasil, Livraria Bertrand e Atlântida); b) duas traduções policopiadas e não publicadas.

Além da publicação enquanto livro ou documento fotocopiado autónomos, surge o caso de um capítulo de livro, com três peças agrupadas numa secção da obra Théâtre espagnol du XVIe siècle, inserida na prestigiada Bibliothèque de la Pléiade, e dirigida por Robert Marras, que confiou ao lusitanista francês Paul Teyssier a selecção e tradução das obras de Gil Vicente que correspondessem à orientação linguística da antologia. A inclusão de Gil Vicente na antologia não surpreende por essa razão, sendo reveladora da posição plural da obra vicentina na História literária: dramaturgo da Corte, produzia em português e em castelhano. As peças do capítulo "Gil Vicente" têm em comum a língua da sua escrita ${ }^{1}$, critério seguido igualmente por Thomas R. Hart, editor da obra referida como fonte para as traduções ${ }^{2}$.

As obras traduzidas são-no na íntegra, mas também é feita referência por Paul Teyssier a uma tradução de fragmentos da peça Pranto de Maria Parda (vide n. 6), uma situação igualmente assinalada pela investigadora francesa Anne-Marie Quint, na comunicação que apresentou em 2002 no Congresso Internacional Gil Vicente 500 anos depois, que cita a publicação de "excertos traduzidos por Agostinho de Campos (in Revue des cours et conférences, n⿳30, juin 1938) e Mme Greloud ("Le mystère de Lusitanie", Bulletin des Études portugaises, nouvelle série, 1939, pp.61-63)” e da tradução de Mme Bobillot intitulada "Le Mystère de la Visitation [Auto da Alma, Auto da Visitação]", in Bulletin des Études portugaises, nouvelle série, 1939"3. Também refere uma tradução não publicada do Auto da Alma da sua autoria, que fez a pedido da docente Teresa Mota-Demarcy, da Universidade de Paris III, em 1994, destinada ao público que iria assistir à representação da obra pelos estudantes (o.c., pp.273-274).

\footnotetext{
${ }^{1}$ Por essa razão, a selecção exclui a tradução de uma farsa: "Aucune farce ne pouvait prendre place ici, car les farces de Gil Vicente sont toujours écrites en portugais, ce qui les met en dehors du champ de la présente anthologie » (Teyssier in Marras1983 :882)

${ }^{2}$ Gil Vicente, Obras dramáticas castellanas, edición, estúdio y notas de Thomas R. Hart, Clásicos castellanos, Madrid, 1962. I.S.Révah também é referido enquanto autor do texto-fonte para a tradução da Tragicomedia de Dom Duardos. Trata-se do artigo "Édition critique du "romance" de Don Duardos e Flérida", Bulletin d'histoire du théâtre portugais, III, 1952, pp.136-137.

${ }^{3}$ As informações aqui transcritas reproduzem parcialmente a nota 1 da comunicação (2003: 273).
} 
VICENTE, Gil, (1955), La barque d'enfer, traduit du portugais par Claude-Henri Frèches, d'après l'édition critique du «Premier Auto das Barcas» par. I. S. Révah, Lisboa, Imprensa Portugal-Brasil, Lisboa [édition publiée sous les auspices de l'Institut Français au Portugal à l'occasion du Festival International d'Art Dramatique (Paris-1955)].

-- (1956), Les Indes (Auto da Índia), traduction de Claude-Henri Frèches, Lisboa, Livraria Bertrand, tirage à part du Bulletin des Études Portugaises, t.19 ${ }^{4}$.

-- (1958), Trilogie des barques [Moralité de la barque de l'enfer, Moralité de la barque du purgatoire, Moralité de la barque de la gloire], traduction et préface de Andrée Crabbé Rocha, Coimbra, Atlântida [Publication du Théâtre des Étudiants de l'Université de Coimbra pour le Festival International de Théâtre Universitaire à l'Exposition Internationale de Bruxelles]

-- (1983), Auto de la Sybille Cassandre (Auto da Sibila Cassandra) ; Auto de la Barque du Paradis (Auto da Barca da Glória); Tragi-comédie de Don Duardos (Tragicomedia de Dom Duardos), textes présentés, traduits et annotés par Paul Teyssier, in Robert Marras (sous la dir.) Théâtre espagnol du XVIe siècle, Paris, Gallimard, Bibliothèque de la Pléiade, pp.203-269.

VICENTE, Gil, (1995?), Le triomphe de l'hiver / O Triunfo do Inverno, Dossier établi par Paul Teyssier, texto policopiado, s.d.

-- (1995), La complainte de Maria Parda, trad. Carlos Leite, texto policopiado ${ }^{5}$.

-- (1995), La plainte de Maria la noiraude (Pranto de Maria Parda), introduction, traduction française et notes de Paul Teyssier, édition bilingue, Paris, Éditions Chandeigne, Théâtre de Gil Vicente $\mathrm{I}^{6}$.

\footnotetext{
${ }^{4}$ Encontra-se em depósito na Biblioteca da Faculdade de Letras da Universidade de Lisboa no espólio legado por Osório Mateus (UFLOM05786).

5 Encontra-se em depósito na Biblioteca da Faculdade de Letras da Universidade de Lisboa no espólio legado por Osório Mateus (UFLOM0608).

${ }^{6}$ Assinala uma tradução anterior das treze primeiras estrofes do Pranto inseridas em: Anthologie de la Poésie portugaise du XIIe au XXe siècle, organisée par Isabel Meyrelles, Paris NRF, Gallimard, 1971, pp.51-55 (1995:88-89). Anne-Marie Quint (2003:273, n.1) também cita traduções (provavelmente de excertos) da obra de Gil Vicente inseridas na obra Poésies et chansons, choix de textes, trad. de Guy Levis Mano , Paris, G.L.M., 1970".
} 
-- (1997), Le triomphe de l'hiver (Triunfo do Inverno e do Verão), introduction, traduction française et notes de Paul Teyssier, édition bilingue, Paris, Éditions Chandeigne, Théâtre de Gil Vicente II ${ }^{7}$.

-- (1997), Le Jeu de l'âme (Auto da Alma); Le Jeu de la Foire (Auto da Feira), édition critique, introduction, traduction française et notes d'Anne-Marie Quint, édition bilingue, Paris, Éditions Chandeigne, Théâtre de Gil Vicente III.

-- (1997), La farce des muletiers (A Farça dos Almocreves), éd. critique, introduction, traduction française et notes d'Olinda Kleiman, édition bilingue, Paris, Éditions Chandeigne, Théâtre de Gil Vicente IV.

-- (2000), La barque de l'enfer (Auto da Barca do Inferno), introduction, traduction française et notes de Paul Teyssier, édition bilingue, Paris, Éditions Chandeigne, Théâtre de Gil Vicente V.

-- (2011), Plainte de Maria la Noiraude, introduction, traduction française et notes de Paul Teyssier; ${ }^{8}$ Farce d'Inês Pereira, introduction, traduction française et notes de Bernard Martocq, Paris, Librairie Portugaise-Éditions Chandeigne, Théâtre de Gil Vicente, vol. VI.

A apresentação da lista numa sequência cronológica, em que a tradução de obras de Gil Vicente, com publicação, tem início em 1955 e se prolonga até 2011, com uma interrupção após 1975 e um recomeço em 1995, evidencia um interesse reforçado pela dramaturgia vicentina a contar dessa última data. Marcada por um modelo de publicação de tipo antológico, a tradução passa a ter um carácter sistemático que configura um verdadeiro programa editorial, assumido pelo editor Michel Chandeigne, com a colaboração do especialista dos estudos portugueses, Paul Teyssier'

\footnotetext{
${ }^{7} \mathrm{O}$ mesmo tradutor é autor da tradução não publicada referida no nosso corpus com o título: VICENTE, Gil (1995?), Le triomphe de l'hiver / O Triunfo do Inverno, Dossier établi par Paul Teyssier, texto policopiado, s.d..

${ }^{8}$ Acerca da tradução do Pranto, publicada em 1995 e também da sua autoria, Teyssier refere o seguinte: "Par rapport à notre présente édition, celle-ci présentait en sus un fac-similé des éditions de 1522 et 1562 , ainsi qu'une annexe de six pages traitant de l'établissement du texte, des principes de transcription et de la versification $»(2011: 184)$.

${ }^{9}$ Sobre o editor Michel Chandeigne, consultar Zurbach 2003, pp. 303-321.
} 
Em termos quantitativos, tratando-se de um autor canónico da língua e da cultura portuguesas, surpreende o número total relativamente baixo de traduções produzidas até hoje, bem como o número igualmente reduzido de editoras francesas interessadas, comparativamente inferior ao das editoras portuguesas. $\mathrm{Na}$ verdade, confirma-se no caso de Gil Vicente, por um lado, a marginalidade da recepção da literatura portuguesa em tradução no sistema literário francês e, por outro lado, o facto de o género dramático ser o menos representado no conjunto das obras importadas na cultura francófona. Notese, no entanto, um interesse pela promoção da acessibilidade da obra em edições críticas bilingues, claramente situadas no campo da promoção da língua e do teatro portugueses num contexto francófono culto.

A cronologia é reveladora do papel representado pela instituição universitária portuguesa na primeira fase de divulgação do teatro vicentino em língua francesa nos anos 1950-60', período após o qual a promoção e o reforço das relações culturais lusofrancesas deu passos significativos graças ao envolvimento dos responsáveis pelos estudos portugueses na universidade francesa, progressivamente autonomizados no campo dos estudos ibéricos a partir dos anos 1980' e 90,10, com um contributo reforçado para a produção de traduções eruditas até hoje ${ }^{11}$.

Um traço curioso merece uma nota, dado a raridade da edição da tradução de teatro realizada para a leitura ou para o palco. O caso em análise revela uma articulação imediata com a natureza performativa e teatral do género, num contexto de recepção igualmente sensível à sua especificidade cultural. Com efeito, para duas peças do nosso corpus, as traduções realizadas visam uma apresentação cénica que projectam Gil Vicente no meio cultural francófono enquanto dramaturgo de pleno direito. Num dos casos, a obra traduzida entra em diálogo com a interpretação cénica: enunciada no palco na língua de origem pelos estudantes de Coimbra, a tradução intitulada na versão em língua francesa Trilogie des Barques, resulta de uma encomenda circunstancial. Publicada por uma editora portuguesa, é antecipadamente posta à venda nas livrarias para o público potencial das representações pelo grupo estudantil TEUC, convidado

\footnotetext{
${ }^{10}$ O volume da colecção Pléiade (Marras 1983) ainda é um exemplo do predomínio do estudo da literatura e do teatro espanhol em França. Gil Vicente apenas consta na antologia pelo uso do castelhano nas obras escolhidas.

${ }^{11}$ Merecem uma consulta as publicações pela Fundação Calouste Gulbenkian de Paris das Actas de colóquios sobre as relações literárias luso-francesas que tiveram lugar em Paris ao longo da década de 1980 .
} 
para o Festival International de Théâtre Universitaire (FITU) organizado pela Comissão da Exposição Universal de Bruxelas em $1958^{12}$.

Em termos de selecção dos textos no conjunto dos géneros que caracterizam a obra vicentina, as traduções incidem predominantemente nos Autos ditos das Barcas, com quatro casos entre 1955 e 1962 e uma nova tradução em 2000, e no Pranto de Maria Parda, com duas traduções por tradutores diferentes no mesmo ano de 1995 e a reedição de uma delas em 2011. Apenas a edição antológica das Editions Chandeigne introduz uma diversificação dos géneros contemplados pelos editores, com duas farsas e uma peça intitulada "triunfo", concebida para festejos cortesãos.

Os tradutores são todos especialistas dos estudos portugueses, de nacionalidade francesa ou portuguesa, com funções docentes ou culturais nos domínios da promoção da língua, da literatura e da cultura portuguesas, com uma proximidade diversificada do teatro de Gil Vicente e da sua encenação. Com maior proximidade, encontramos Claude-Henri Frèches (1955) e Crabbé Rocha (1958) que traduzem para festivais ou encontros universitários internacionais, que envolvem $\operatorname{artistas}^{13}$ ou estudantes de universidades portuguesas.

Também os universitários e tradutores franceses Olinda Kleiman, Anne-Marie Quint e Bernard Martocq, na apresentação das peças que traduziram a convite do editor Chandeigne para um público identificável com o meio estudantil e académico ${ }^{14}$, não deixam de salientar, em graus diversos, o valor teatral das obras.

O papel de Paul Teyssier na consolidação da importação da obra vicentina para um contexto francófono merece destaque. A publicação, entre 1995 e 2011, de seis

\footnotetext{
${ }^{12}$ A escolha de Gil Vicente responde à orientação dada "(pelos) organizadores (que) pediam que cada grupo representasse teatro do seu próprio país" (Soares 1961:309); a tradução, "feita num "francês delicioso, levemente arcaico" (id.: 311) foi encomendada "à pena de Andrée Crabbé Rocha, distinta senhora belga, que foi amiga do TEUC nos seus primeiros tempos e é profunda conhecedora da nossa língua e da nossa literatura dramática" (ibid., id.).

${ }^{13}$ Em nota introdutória da tradução intitulada La Barque d'enfer (1955), Pierre Hourcade escreve: "Tel est le grand écrivain, à peine connu en France de quelques érudits spécialistes, dont l'Auto de la Barque de l'Enfer, l'une des réussites les plus achevées, apportera pour la première fois la révélation aux auditoires du Festival. Je souhaite que leur amicale adhésion rende justice à ses mérites, si dignement servis par la ferveur et le talent des artistes du Théâtre National de Lisbonne » (ibid.. : 10).

${ }^{14}$ No caso da editora Chandeigne, a tradução é acompanhada por um conjunto de elementos paratextuais de grande erudição: edição bilingue, edição crítica, introdução, notas, fixação e transcrição do texto original, facsimiles das edições, bibliografia exaustiva.
} 
volumes da colecção do "Théâtre de Gil Vicente" ${ }^{15}$, inserida na Série Lusitane dirigida por Anne Lima e Michel Chandeigne, fundador das Éditions Chandeigne - Librairie Portugaise em Paris, constitui o maior projecto em torno da tradução vicentina em língua francesa, com a particularidade de corresponder a um plano editorial programático, refletido num catálogo essencialmente preenchido por obras e assuntos luso-brasileiros.

O corpus também é revelador da posição da tradução na cultura actual. Com efeito, o discurso dos tradutores sobre a tradução em geral ou sobre o caso particular do teatro de Gil Vicente, patente nas edições anotadas ou comentadas, dá-nos conta de uma evolução que, partindo da ausência de qualquer referência aos problemas da tradução no caso de Andrée Crabbé Rocha, acaba na afirmação da especialização do tradutor ao serviço da editora Chandeigne. Patente no volume do discurso prefacial, o tradutor entrou em sintonia com a valorização da tradução no mundo actual, quer enquanto prática exigente, quer enquanto objecto de estudo.

Não foram abordadas aqui outras vertentes do estudo da tradução, nomeadamente a descrição e a análise dos textos enquanto resultado das circunstâncias aqui descritas em termos socioculturais com particular incidência na edição das traduções listadas. A crítica da tradução encontraria aqui matéria para reflexão, nomeadamente no que diz respeito à identificação das normas (Toury 1995) presentes nas opções dos tradutores. De facto, a leitura das traduções aqui citadas permite detectar, ainda que numa leitura superficial e rápida, traços semelhantes aos que se colocam ao tradutor de textos datados como é o caso para a obra de Shakespeare, por exemplo. Da tradução filológica, marcadamente literária, à tradução elaborada para um projecto cénico específico, traduzir autores do passado tem os contornos de um processo constantemente reaberto, com opções variáveis ao longo das escassas décadas aqui envolvidas, mas em que a prática de reescrita dos tradutores evidencia a busca de uma eficácia dos textos em termos teatrais, aproximados da sua performatividade de origem, de modo a fazer justiça a Gil Vicente, ao dramaturgo, que foi sobretudo homem de palco.

\footnotetext{
${ }^{15}$ A publicação da colecção tem o apoio do Centre National du Livre (Paris), do Instituto da Biblioteca Nacional e do Livro, e do Instituto Camões (Lisbonne.).
} 


\section{Bibliographie}

Bassnett, Susan, Estudos de Tradução, Lisboa, FCG, trad. V. Campos Figueiredo [1980].

Casanova, Pascale (1999), La République mondiale des Lettres, Paris, Seuil.

Delabastita, Dirck \& al. (2006), Functional Approaches to Culture and Translation.

Selected papers by José Lambert, Amsterdam/Philadelphia, John Benjamins.

Keates, Laurence (1988), O Teatro de Gil Vicente na Corte, Lisboa, Teorema.

Quint, Anne-Marie (2003), "O Teatro religioso de Gil Vicente à luz da tradução: Auto da Alma

e Auto da Feira, in Actas do Congresso Internacional: Gil Vicente - 500 anos depois, Lisboa, INCM, vol. I, pp. 273-284.

Soares, A.J (1961), Subsídios para a história do Teatro dos Estudantes da Universidade de Coimbra (1938-1961), Coimbra, VIII Delfíada.

Teyssier, Paul (1959), La Langue de Gil Vicente, Paris, Klincksieck.

Toury, Gideon (1995), "The Nature and Role of Norms in Translation», Descriptive Translation Studies and beyond, Amsterdam/Philadelphia, John Benjamins.

Zurbach, Christine (2003), "Du discours des traducteurs contemporains du théâtre de Gil Vicente en langue française", in Actas do Congresso Internacional: Gil Vicente - 500 anos depois, Lisboa, INCM, vol. I, pp. 303-321.

(2004), "Normes et modèles dans la traduction française du théâtre

de Gil Vicente" in Actas do IV Congresso da Associação Portuguesa de Literatura Comparada: Estudos Literários/ Estudos Culturais, Carlos J.F. Jorge e Christine Zurbach (eds), Universidade de Évora. 